\title{
Effect of sildenafil on acrolein-induced airway inflammation and mucus production
} in rats

\author{
T. Wang*, , Y. Liu*, ${ }^{\star}$, L. Chen*, X. Wang*, X-R. Hu*, Y-L. Feng*, D-S. Liu*, D. Xu*, \\ Y-P. Duan ${ }^{\#}$, J. Lin*, X-M. Ou* and F-Q. Wen*
}

ABSTRACT: Airway inflammation with mucus overproduction is a distinguishing pathophysiological feature of many chronic respiratory diseases. Phosphodiesterase (PDE) inhibitors have shown anti-inflammatory properties. In the present study, the effect of sildenafil, a potent inhibitor of PDE5 that selectively degrades cyclic guanosine 3', 5'-monophosphate (cGMP), on acrolein-induced inflammation and mucus production in rat airways was examined.

Rats were exposed to acrolein for 14 and 28 days. Sildenafil or distilled saline was administered intragastrically prior to acrolein exposure. Bronchoalveolar lavage fluid (BALF) was acquired for cell count and the detection of pro-inflammatory cytokine levels. Lung tissue was examined for cGMP content, nitric oxide (NO)-metabolite levels, histopathological lesion scores, goblet cell metaplasia and mucin production.

The results suggested that sildenafil pretreatment reversed the significant decline of cGMP content in rat lungs induced by acrolein exposure, and suppressed the increase of lung NO metabolites, the BALF leukocyte influx and pro-inflammatory cytokine release. Moreover, sildenafil pretreatment reduced acrolein-induced Muc5ac mucin synthesis at both mRNA and protein levels, and attenuated airway inflammation, as well as epithelial hyperplasia and metaplasia.

In conclusion, sildenafil could attenuate airway inflammation and mucus production in the rat model, possibly through the nitric oxide/cyclic guanosine $3^{\prime}, 5^{\prime}$-monophosphate pathway, and, thus, might have a therapeutic potential for chronic airway diseases.

KEYWORDS: Airway inflammation, cyclic guanosine $3^{\prime}, 5^{\prime}$-monophosphate, goblet cell metaplasia, mucin synthesis, phosphodiesterase-5 inhibitor

$\mathbf{T}$ he lung airway is a primary interface with the outside world and a key target of the environmental stimuli that may trigger inflammatory immune responses. Mucus composed of water, ions, proteins, lipids and mucin glycoproteins coats the luminal surface of the airway and is an important part of the innate immune defence system against toxins and pathogens [1]. However, excessive mucus accumulation with epithelial hyperplasia could contribute to airway obstruction in patients with chronic obstructive pulmonary disease (COPD), asthma or cystic fibrosis (CF), and it is an important factor associated with the morbidity and mortality of these diseases [2]. Enhanced airway inflammation with mucus hypersecretion in response to inhaled noxious particles or gases from tobacco smoke or other environmental agents is considered to be a fundamental characteristic in COPD patients [3].
Acrolein, a reactive $\alpha, \beta$-unsaturated aldehyde, is a toxin to which humans are exposed through a variety of environmental situations, especially as a component of cigarette smoke and automobile exhaust. It has also been identified as both a product and an initiator of lipid peroxidation [4]. The toxicity of acrolein in mammal cells is mainly due to its downstream signalling via cellular oxidative stress, such as glutathione depletion and subsequently reactive oxygen species (ROS) simulation [5]. Recently, it has been evidenced that acrolein is one of the major mediators of cigarette smoke-induced macrophage activation, since it releases both tumour necrosis factor (TNF)- $\alpha$ and interleukin (IL)- 8 from human alveolar macrophages [6]. Acrolein-induced proinflammatory responses are also mediated through the induction of cyclooxygenase- 2 and prostaglandin in both endothelial cells and

\section{AFFILIATIONS}

${ }^{*}$ Division of Pulmonary Diseases, State Key Laboratory of Biotherapy of China and Dept of Respiratory Medicine, West China Hospital of Sichuan University

Chengdu, Sichuan, and

\#Dept of Biochemistry, Tibet University Medical College Lhasa, Tibet, China.

"Both authors contributed equally to this article

CORRESPONDENCE

$\mathrm{F}-\mathrm{Q}$. Wen

Division of Pulmonary Diseases,

State Key Laboratory of Biotherapy of

China and Dept of Respiratory Medicine

West China Hospital of Sichuan

University

Chengdu

Sichuan 610041

China

Fax: 862885582944

E-mail: wenfuqiang.scu@gmail.com

or wenfuqiang@126.com

Received:

April 132008

Accepted after revision:

December 032008

SUPPORT STATEMENT

The current study was supported by grants 30425007, 30370627 and 30670921 from the National Natural Science Foundation of China (Beijing, China) and 00-722 and 06-834 from China Medical Board of New York (New York, USA) to F-Q. Wen.

STATEMENT OF INTEREST

None declared.

European Respiratory Journal Print ISSN 0903-1936

Online ISSN 1399-3003 
human bronchial epithelial cells $[7,8]$. From in vivo studies, it is well established that exposure to acrolein can induce bronchial hyperresponsiveness, mucus overproduction and lung inflammation in animal models [9-11]. Moreover, acrolein has been recently reported to markedly inhibit the generation of cyclic guanosine $3^{\prime}, 5^{\prime}$-monophosphate (cGMP), an important second messenger, in rats [12]. However, the underlying mechanisms remain unclear.

cGMP serves as a second messenger participating in various signalling pathways and regulating many aspects of cell function. Besides the classical regulatory role of cGMP in smooth muscle relaxation and vascular tone regulation, numerous other physiological roles have recently been discovered. For example, it has been reported that cGMP signalling is involved in the downregulation of P-selectin expression and leukocyte recruitment in mice [13]. Pharmacologically increasing cGMP levels in CF respiratory epithelial cells can correct several aspects of the downstream pathology in CF [14]. cGMP analogues also have shown some anti-inflammatory activity through inhibiting lipopolysaccharide (LPS)-induced TNF- $\alpha$ secretion in both human monocytes and murine macrophages [15, 16]. Furthermore, elevated intracellular cGMP levels have been found to inhibit the TNF- $\alpha$-induced increase of nitric oxide (NO)-metabolite levels and inducible NO synthase (iNOS) expression in rat tracheal smooth muscle cells [17]. The concentration of intracellular cGMP depends on a balance between synthesis by soluble guanylate cyclases (sGCs) and degradation by cyclic nucleotide phosphodiesterases (PDEs). The activity or expression of sGCs and PDEs could be modified in various situations. For instance, ROS, TNF- $\alpha$ and excessive NO are all indicated to reduce sGC expression [18-20], while PDE activities are largely increased in oxidative stress and inflammatory processes [21, 22]. Therefore, sGC activators or PDE inhibitors may have therapeutic potential in the treatment of inflammatory diseases. Among these pharmacological agents, PDE5 inhibitors appear to be particularly applicable in treating pulmonary diseases, since PDE5 is expressed in high levels in lung tissue and is highly specific for the hydrolysis of cGMP [23].

Sildenafil is a potent and selective PDE5 inhibitor that promotes the accumulation of intracellular cGMP. It has been reported to be 240 times more potent than the earlier generation PDE5 inhibitor, zaprinast, against PDE5 [24]. Sildenafil is now commonly used in clinical treatment for erectile dysfunction. Recently, it has been intensively studied in the treatment of pulmonary arterial hypertension [25, 26], hyperoxia or hypoxia-induced lung injury [27, 28] and airway diseases [14, 29]. Thus, the aim of the present study was to examine the effect of sildenafil on airway inflammation, goblet cell metaplasia and mucin synthesis in a rat model induced by acrolein inhalation. The results imply for the first time that the PDE5 inhibitor could attenuate acrolein-induced airway inflammation and mucus production.

\section{MATERIALS AND METHODS}

\section{Animals, acrolein exposure and sildenafil treatment}

Specific pathogen-free, male Sprague-Dawley rats, weighing 200-250 g, were used in the current study. All experimental protocols were approved by the Institutional Animal Care and Use Committee of Sichuan University (Chengdu, China). A solution of acrolein (Sigma, St Louis, MO, USA) at a concentration of $3 \mathrm{ppm}\left(6.87 \mu \mathrm{g} \cdot \mathrm{L}^{-1}\right.$ in sterile water) was nebulised into a $0.12 \mathrm{~m}^{3}(40 \times 50 \times 60 \mathrm{~cm})$ exposure chamber with an air flow rate of $30 \mathrm{~L} \cdot \mathrm{min}^{-1}$. The concentration of acrolein in the chamber was monitored using the method previously described [30]. Briefly, chamber air was passed through a series of two glass-fritted impingers, each of which contained a solution of ethanol (49.4\%), trichloroacetic acid (29.7 M), 4-hexylresorcinol (50 mM) and mercuric chloride $(2.1 \mathrm{mM})$. The absorbance was determined at $605 \mathrm{~nm}$ by spectrophotometry $1 \mathrm{~h}$ after collection. The actual acrolein vapour concentration in the present study was found to be $2.46 \pm 0.39 \mathrm{ppm}$. The exposure time was $6 \mathrm{~h} \cdot \mathrm{day}^{-1}, 7 \mathrm{day}-$ $\mathrm{s} \cdot$ week $^{-1}$, for either 14 or 28 days. Control rats were exposed to filtered air under similar conditions. Viagra (sildenafil citrate) tablets were crushed into a fine powder, and $25 \mathrm{mg} \cdot \mathrm{kg}^{-1}$ sildenafil for each rat was suspended in $1 \mathrm{~mL}$ saline and then administered intragastrically $0.5 \mathrm{~h}$ before acrolein exposure.

\section{Tissue preparation}

On day 14 and day 28, rats were anaesthetised intraperitoneally with $3 \mathrm{~mL} \cdot \mathrm{kg}^{-1}$ chloral hydrate and then sacrificed by exsanguination from the abdominal aorta. The trachea was cannulated, and the chest cavity was opened by a midline incision. The left lung was used for bronchoalveolar lavage (BAL). The right middle lobe was fixed and embedded in paraffin for use in morphometric and histochemical studies. The right upper and lower pulmonary lobes were snap frozen in liquid nitrogen and stored at $-80^{\circ} \mathrm{C}$ for homogenisation in the following multiple assays.

\section{cGMP and nitrite/nitrate measurement}

cGMP generation in rat lungs was measured by iodine-125 radioimmunoassay, using a cGMP assay kit (Nuclear Medical Laboratory, Shanghai University of Traditional Chinese Medicine, Shanghai, China) with the reagents provided according to the manufacturer's instructions. Briefly, $50 \mathrm{mg}$ of the snap-frozen lung tissue was homogenated in $2 \mathrm{~mL}$ icecold $50 \mathrm{mM}$ sodium acetate buffer ( $\mathrm{pH} 4.75)$ and then precipitated by the addition of $2 \mathrm{~mL} \mathrm{100 \%} \mathrm{ethanol.} \mathrm{After}$ centrifugation at $1,300 \times g$ for $15 \mathrm{~min}$ at $4^{\circ} \mathrm{C}$, the supernatant was collected and kept on ice. The remaining precipitate was washed again with $75 \%$ ethanol and centrifuged. The second supernatant was mixed with the first one and dried at $60{ }^{\circ} \mathrm{C}$, and it was then re-dissolved in $1 \mathrm{~mL}$ acetate buffer. Then, $100 \mu \mathrm{L}$ solution of each sample was incubated with an acetylating reagent (triethylamine/acetic anhydride $2: 1$ ), ${ }^{125} \mathrm{I}$ cGMP and rabbit antiserum against cGMP overnight at $4^{\circ} \mathrm{C}$. Rabbit serum and sheep anti-rabbit immunoglobulin $G$ were added to the mixture, which was then incubated for $3 \mathrm{~h}$ at room temperature. After centrifugation at $850 \times g$ for $5 \mathrm{~min}$, the pellets were counted for radioactivity by a $\gamma$ counter. cGMP contents were expressed as $\mathrm{pmol} \cdot \mathrm{mg}^{-1}$ fresh weight.

The nitrite and nitrate concentration, an indicator of NO synthesis, was measured in lung homogenate as previously described [31]. Briefly, the frozen lungs were homogenised in $10 \mathrm{mM}$ Tris buffer ( $\mathrm{pH}$ 7.4) containing 1\% Triton X-100, $1 \mathrm{mM}$ EDTA, $1 \mathrm{mM}$ phenylmethyl sulphonyl fluoride (PMSF), $10 \mu \mathrm{g} \cdot \mathrm{mL}^{-1}$ aprotinin and $10 \mu \mathrm{g} \cdot \mathrm{mL}^{-1}$ leupeptin. The nitrate 
in the supernatant was first reduced to nitrite by incubation with nitrate reductase and nicotinamide adenine dinucleotide phosphate. Then the total nitrite concentration in the tissue sample was measured spectrophotometrically at $550 \mathrm{~nm}$ through the Griess reaction. The protein concentration in the lung homogenate was determined by the bicinchoninic acid method (Pierce, Rockford, IL, USA). Data were expressed as $\mathrm{nmol} \cdot \mathrm{mg}^{-1}$ protein.

\section{BAL fluid and cell count}

After rats were exsanguinated via the abdominal aorta, the trachea was cannulated, and the chest cavity was opened by a midline incision. The right main-stem bronchus was ligated, and the left lung was lavaged with $2 \mathrm{~mL}$ followed by two times $1 \mathrm{~mL}$ PBS containing $5 \mathrm{mM}$ EDTA, $5 \mathrm{mM}$ dithiothreitol and $5 \mathrm{mM}$ PMSF. Fluid recovery was always above $85 \%$. Total cell counts were obtained in $0.5 \mathrm{~mL}$ BAL fluid (BALF) aliquots using a haemocytometer. The remaining BALF samples were centrifuged at $15,000 \times g$ for $10 \mathrm{~min}$, and the supernatants were removed and stored at $-80^{\circ} \mathrm{C}$ for the cytokine ELISA. The deposited cells were resuspended in $0.2 \mathrm{~mL}$ PBS, and the differential cell counts were determined in cytospin preparations stained with Wright-Giemsa, counting 200 cells from each animal. An experienced investigator who was blinded to the experimental conditions did all the enumerations based on standard morphological criteria.

\section{Cytokine detection in BALF and lung homogenate}

Lung homogenate was prepared as described in the nitrite/ nitrate measurement. TNF- $\alpha$ and cytokine-induced neutrophil chemoattractant (CINC)-1 (rat homologue for human IL-8) levels in the BALF and lung homogenate were determined using commercially available ELISA kits for rat cytokines (R\&D Systems, Minneapolis, MN, USA). The detection limit for the TNF- $\alpha$ assay was $<5 \mathrm{pg} \cdot \mathrm{mL}^{-1}$, and the minimum detectable dose of rat CINC-1 was $1.1 \mathrm{pg} \cdot \mathrm{mL}^{-1}$.

\section{Lung histopathology and immunohistochemistry}

Lung tissue was fixed in $4 \%$ formaldehyde ( $\mathrm{pH} 7.4$ ), embedded in paraffin, cut into $4 \mu \mathrm{m}$-thick sections and then stained with haematoxylin and eosin (H\&E), and alcian blue (AB) and periodic acid-Schiff (PAS). The degree of lung inflammation was evaluated by the previously described method [32]. Briefly, lung lesions, including alveolar septal infiltrates, perivascular infiltrates, combined bronchus-associated lymphoid tissue hyperplasia, and peribronchiolar infiltrates, were subjectively graded on a numeric scale of 14 , corresponding to minimal, mild, moderate and marked severity, by an experienced pathologist who was blinded to the treatments. Overall, histopathological scores were generated from the average of the individual lesion scores for each rat. For the immunohistochemical detection of mucin Muc5ac, the sections were stained with mouse monoclonal antibody to Muc5ac (clone 45 M1, 1:200; Neomarkers, Fremont, CA, USA), using the VECTASTAIN ${ }_{\circledR}$ ABC kit (Vector Laboratories, Burlingame, CA, USA). Images of the small airways that were $<800 \mu \mathrm{m}$ in diameter were recorded by a semiautomatic imaging system [10]. At least five complete airways per rat were examined. Percentages of positively stained areas, by either AB/PAS or Muc5ac antibody, to the total airway epithelial area were measured by Image-Pro Plus software (Media Cybernetics, Silver Spring, MD, USA).

\section{Western blot analysis}

Lung and stomach homogenates were prepared in lysis buffer, containing $50 \mathrm{mM}$ Tris- $\mathrm{HCl}, 150 \mathrm{mM} \mathrm{NaCl}, 1 \% \mathrm{NP}-40,0.5 \%$ sodium deoxycholate, $2 \mathrm{mM} \mathrm{NaF}, 2 \mathrm{mM}$ EDTA, 0.1\% SDS and a protease inhibitor cocktail tablet (Roche Applied Science, Indianapolis, IN, USA). Western blot analysis for Muc5ac was performed as previously described with a few modifications [33]. Briefly, $100 \mu \mathrm{g}$ total protein for each sample except the stomach sample, which contained $20 \mu \mathrm{g}$ total protein, was separated by SDS-polyacrylamide gel electrophoresis in 6\% acrylamide-bisacrylamide (60:1) gel for $4 \mathrm{~h}$ and then transferred electronically to polyvinylidene difluoride membranes (Millipore, Bedford, MA, USA). The membranes were incubated with a 1:1,000 dilution of mouse monoclonal antibody against Muc5ac (Santa Cruz Biotechnologies, Santa Cruz, CA, USA). The signals were developed using Super-Signal West Pico chemiluminescent substrate (Pierce, Rockford, IL, USA).
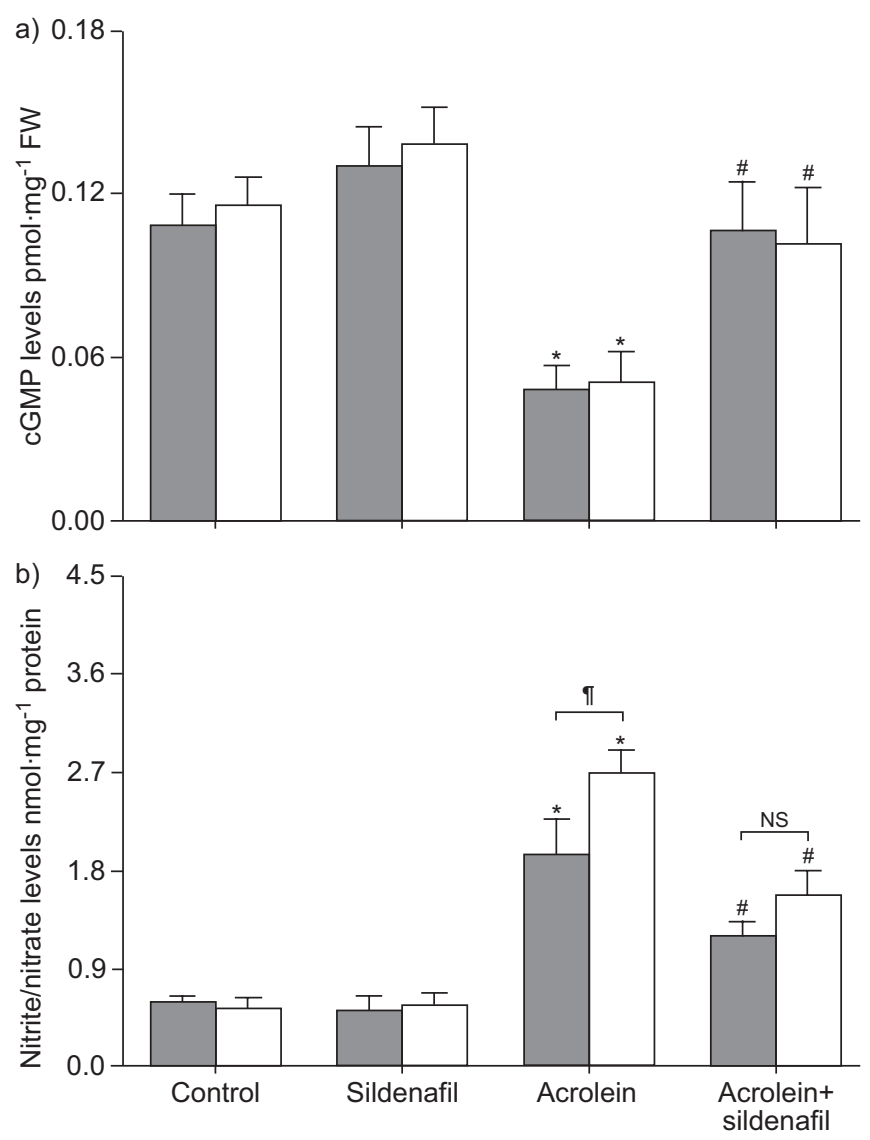

FIGURE 1. Levels of cyclic guanosine $3^{\prime}, 5^{\prime}$-monophosphate (cGMP) and nitrite/nitrate in rat lungs. Rats were exposed to $3.0 \mathrm{ppm}$ acrolein for either 14 ( $\square$ ) or 28 ( $\square$ ) days. a) cGMP levels were determined by iodine-125 radioimmunoassay and expressed per mg lung fresh weight (FW). b) Nitrite/nitrate levels in the lung homogenate were measured with Griess reagent after the conversion from nitrate to nitrite. Values are expressed as mean \pm SD (4-6 animals per group). *: $p<0.05$, significant difference from the control group; ${ }^{\#}: p<0.05$, significant difference from the acrolein-exposed group; ': $p<0.05$, significant difference between 14 and 28 days of acrolein exposure with or without sildenafil treatment. NS: nonsignificant. 


\section{Reverse transcriptase PCR analysis}

Total RNA was isolated using Trizol (Invitrogen, Carlsbad, CA, USA) from the frozen tissue. First-strand cDNA was synthesised from $5 \mu \mathrm{g}$ of total RNA for each sample using moloney murine leukemia virus reverse transcriptase (RT; MBI Fermentas Inc., Burlington, Canada) and random hexamer primer, according to the manufacturer's instructions. The PCR program for both Muc5ac and $\beta$-actin was initiated by a 2 min denaturation step at $94^{\circ} \mathrm{C}$, followed by 30 cycles of $94^{\circ} \mathrm{C}$ for $30 \mathrm{~s}, 58^{\circ} \mathrm{C}$ for $30 \mathrm{~s}$ and $72^{\circ} \mathrm{C}$ for $45 \mathrm{~s}$, and a final extension at $72^{\circ} \mathrm{C}$ for $5 \mathrm{~min}$. Primers for Muc5ac PCR (500 bp) were (forward) 5'-GCT CAT CCT AAG CGA CGT CT-3' and (reverse) 5'-GGG GGC ATA ACT TCT CTT GG-3'. Primers for $\beta$-actin PCR (200 bp) were (forward) $5^{\prime}$-CCT CAT GAA GAT CCT GAC CG-3' and (reverse) 5'-ACC GCT CAT TGC CGA TAG TG-3'. PCR products were electrophoresed on a $1.5 \%$ agarose gel and visualised by ethidium bromide staining. Densitometry was carried out using a Bio-Rad ChemiDoc image acquisition system and Quantity One (v4.6) quantitation software (Bio-Rad, Hercules, CA, USA).

\section{Statistical analysis}

All values were expressed as mean $\pm \mathrm{SD}$. Statistical analysis was carried out using one-way ANOVA, followed by Tukey's honestly significant differences test (equal variances) or
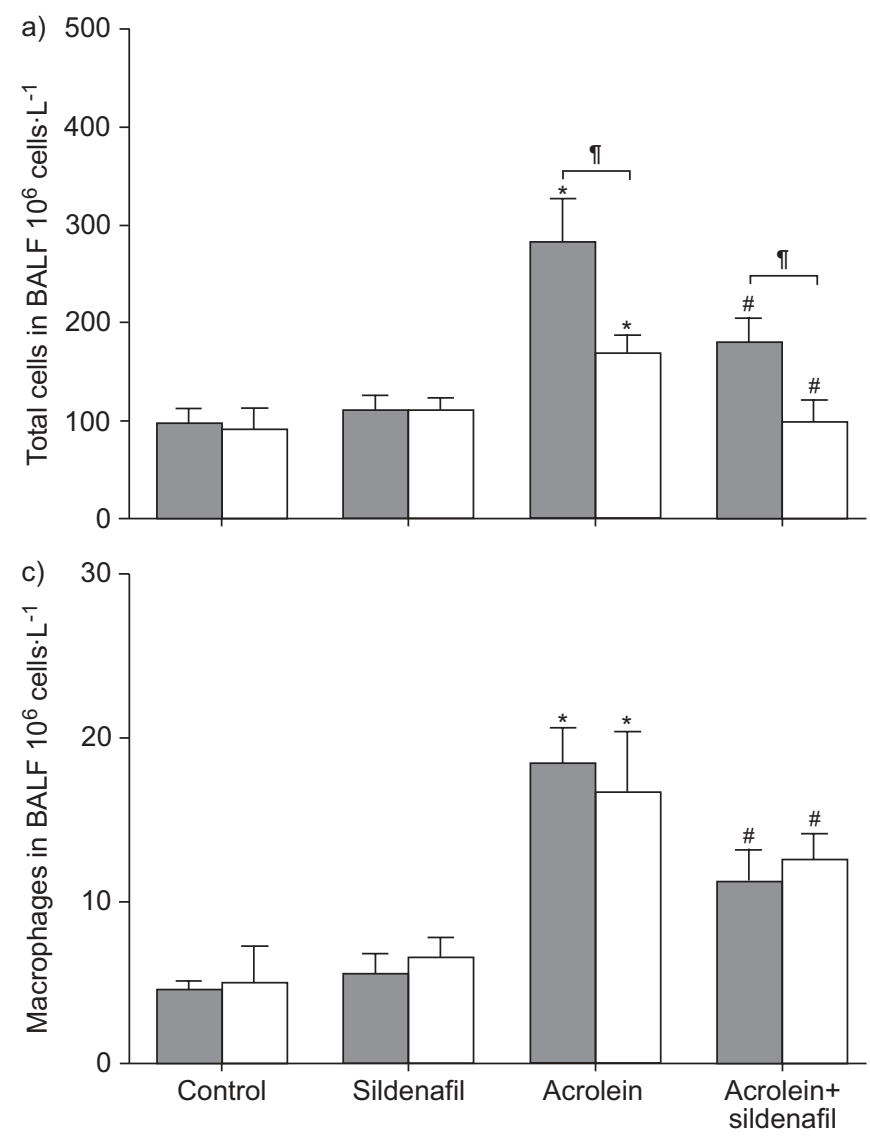

Dunnett's T3 test (unequal variances) for post hoc multiple comparisons. A significant difference was accepted at $\mathrm{p}<0.05$.

\section{RESULTS}

\section{Effect of acrolein exposure and sildenafil treatment on levels of cGMP and NO-metabolites in rat lungs}

Previously, it was shown that acrolein inhibited cGMP generation in rat plasma [12]. To test whether cGMP levels are altered in the lung by acrolein and sildenafil, rats were pretreated with sildenafil or not and then exposed to $3.0 \mathrm{ppm}$ acrolein for either 14 or 28 days, and the cGMP levels in lung homogenate were examined using radioimmunoassay. As shown in figure 1a, acrolein significantly decreased (by nearly 50\%) the cGMP levels in the lungs of the acrolein-exposed rats compared with the control rats $(p<0.05 ; 4-6$ animals per group). No significant difference was found among the control groups, the groups treated with sildenafil alone and the groups treated with acrolein plus sildenafil for both 14 and 28 days. Meanwhile, there was a significant difference between the groups exposed to acrolein only and the groups treated with acrolein plus sildenafil, which suggested that the decline of cGMP levels induced by acrolein exposure could be restored by sildenafil administration.

To determine whether NO synthesis in the lung was also changed by acrolein exposure and sildenafil intervention, the
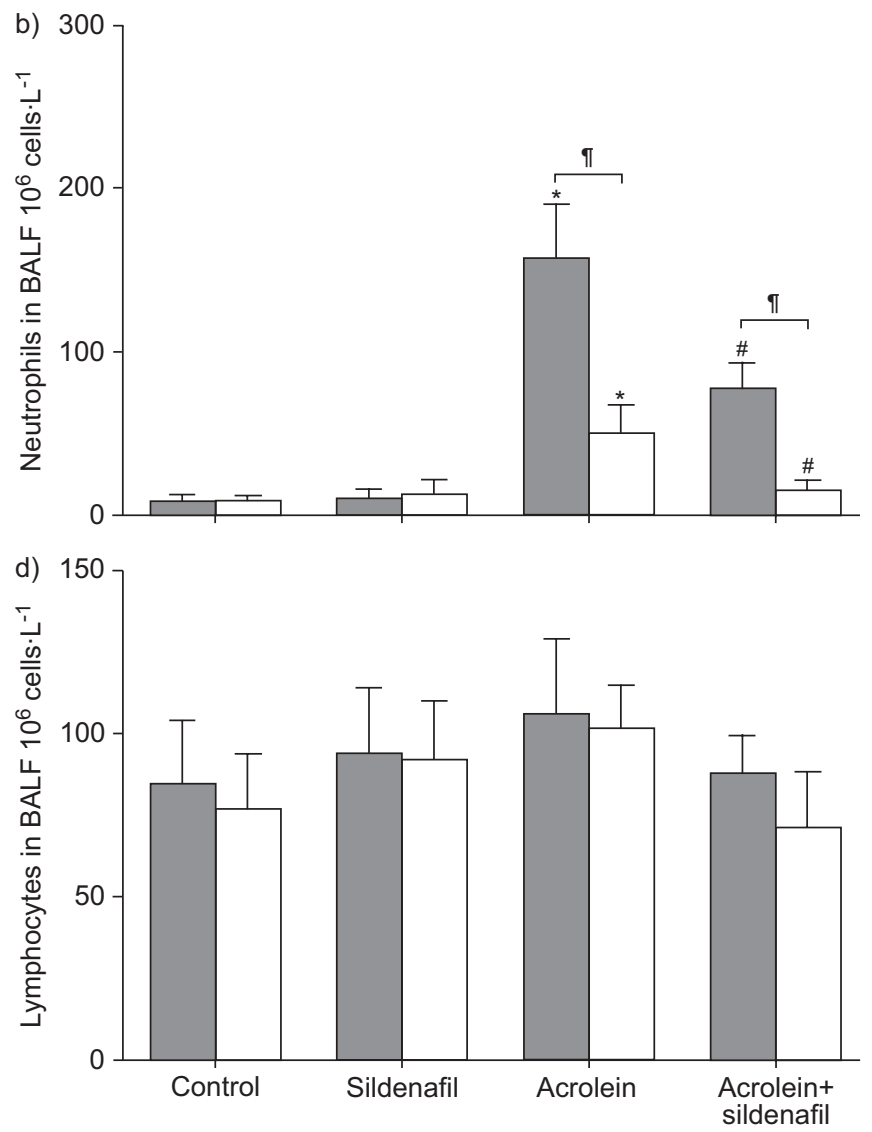

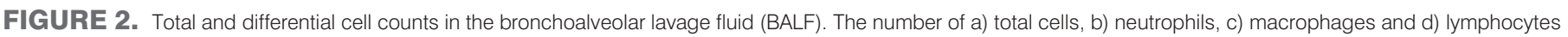

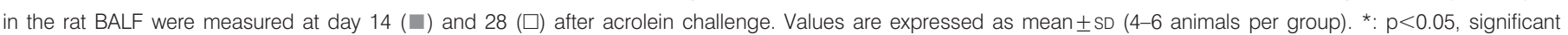

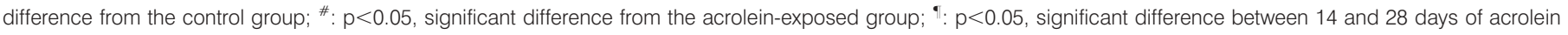
exposure with or without sildenafil treatment. 

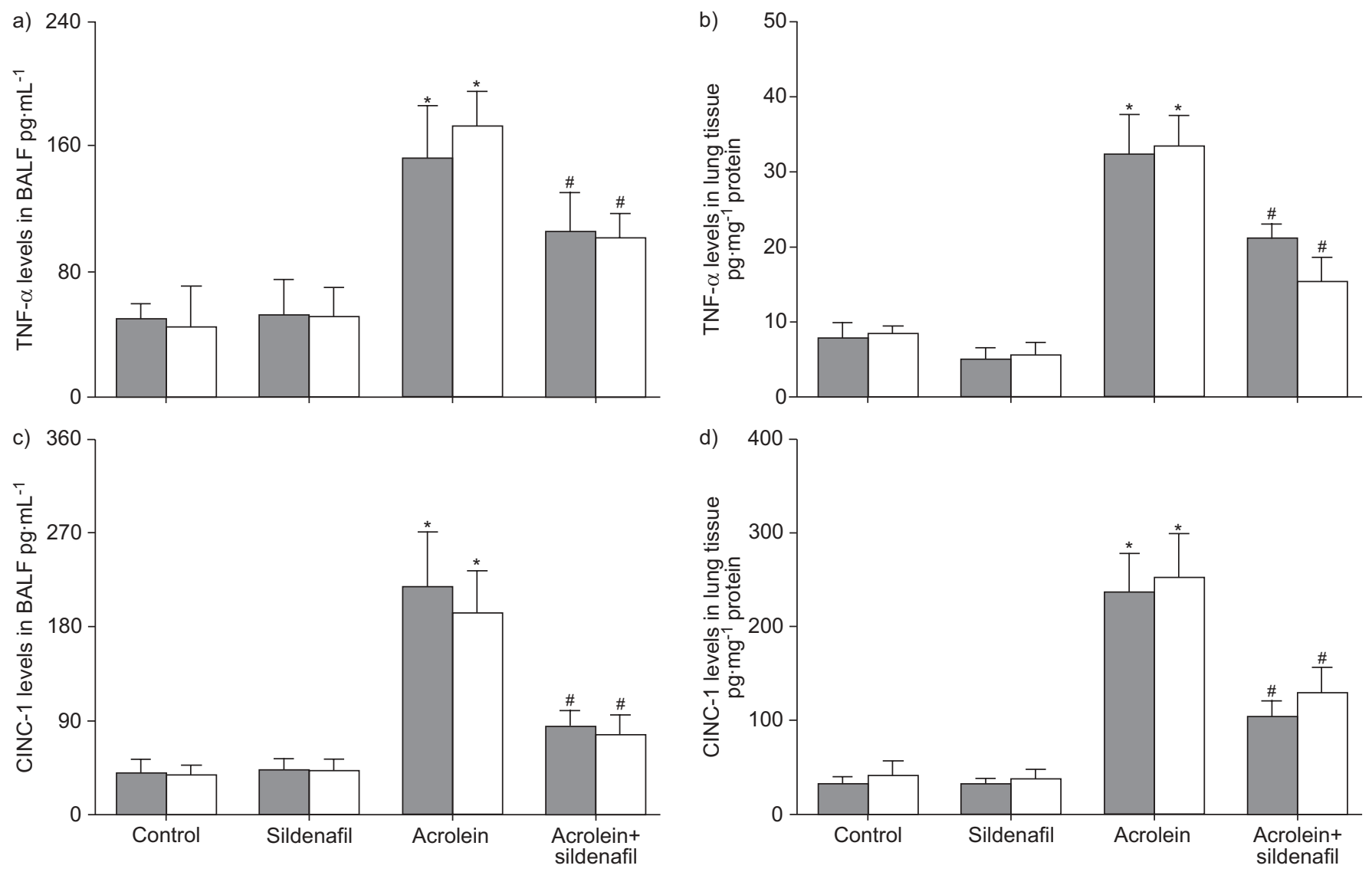

FIGURE 3. Levels of $a$ and $b$ ) tumour necrosis factor (TNF)- $\alpha$ and $c$ and d) cytokine-induced neutrophil chemoattractant (CINC)- 1 in the bronchoalveolar lavage fluid (BALF) and lungs. Cytokines were determined by ELISA in both a and c) the BALF and b and d) lung homogenate. Values are expressed as mean \pm SD (4-6 animals per group). *: $p<0.05$ significant difference from the control group; ${ }^{*}: p<0.05$, significant difference from the acrolein-exposed group. $\square: 14$ days acrolein exposure; $\square: 28$ days acrolein exposure.

levels of stable end-products of NO metabolism (nitrite/ nitrate) were examined. The results demonstrated that nitrite and nitrate levels in rat lungs were significantly elevated after subchronic acrolein inhalation, and a trend towards even higher NO-metabolite levels was observed in rats exposed to acrolein for 28 days compared with those exposed for 14 days. Sildenafil administration markedly reduced the elevated NOmetabolite levels induced after acrolein exposure at both 14 and 28 days, indicating that the acrolein inhalation-induced excessive NO production could be attenuated by sildenafil treatment (fig. 1b).

\section{Effect of sildenafil on acrolein-induced leukocyte influx in BALF}

To investigate the effect of sildenafil on acrolein-induced leukocyte influx in rat airways, total and differential cell counts were performed in the BALF. Total BALF leukocyte counts were significantly higher in acrolein-exposed groups than in control groups at both 14 and 28 days, but decreased over time (fig. 2a). BALF cell differential counts revealed that the number of lymphocytes did not differ among all treated and control groups (fig. 2d). In contrast, the numbers of neutrophils and macrophages in the BALF were significantly increased after acrolein inhalation for 14 and 28 days, compared with the controls (fig. $2 \mathrm{~b}$ and $2 \mathrm{c}$ ). In the acrolein-exposed groups, macrophage accumulation remained elevated for the duration of the subchronic exposure period, whereas the number of neutrophils tended to decrease over time. Sildenafil administration remarkably reduced the acrolein-induced recruitment of neutrophils and macrophages in the BALF, and there were significant differences of neutrophil and total cell counts in sildenafil treatment between 14 and 28 days of acrolein exposure (fig. 2). The results suggested that sildenafil treatment could partially suppress the increase of inflammatory cell influx in the BALF induced by acrolein exposure.

\section{Effect of sildenafil on acrolein-induced pro-inflammatory cytokine release in BALF and lungs}

Since acrolein was previously reported to release both TNF- $\alpha$ and IL- 8 from human macrophages [6], ELISA for TNF- $\alpha$ and CINC-1 (rat analogue of human IL-8) in the BALF and lung tissue was used to determine the effect of sildenafil on acrolein-induced pro-inflammatory response in rats. After acrolein exposure for 14 and 28 days, TNF- $\alpha$ and CINC-1 levels were both significantly elevated in the BALF (fig. 3a and c) and the lung homogenate (fig. $3 b$ and d) compared with the controls. Intragastrical administration of sildenafil before acrolein challenge significantly reduced the increase in TNF- $\alpha$ and CINC-1 release induced after acrolein inhalation in the BALF, as well as in the lung tissue (fig. 3). No 

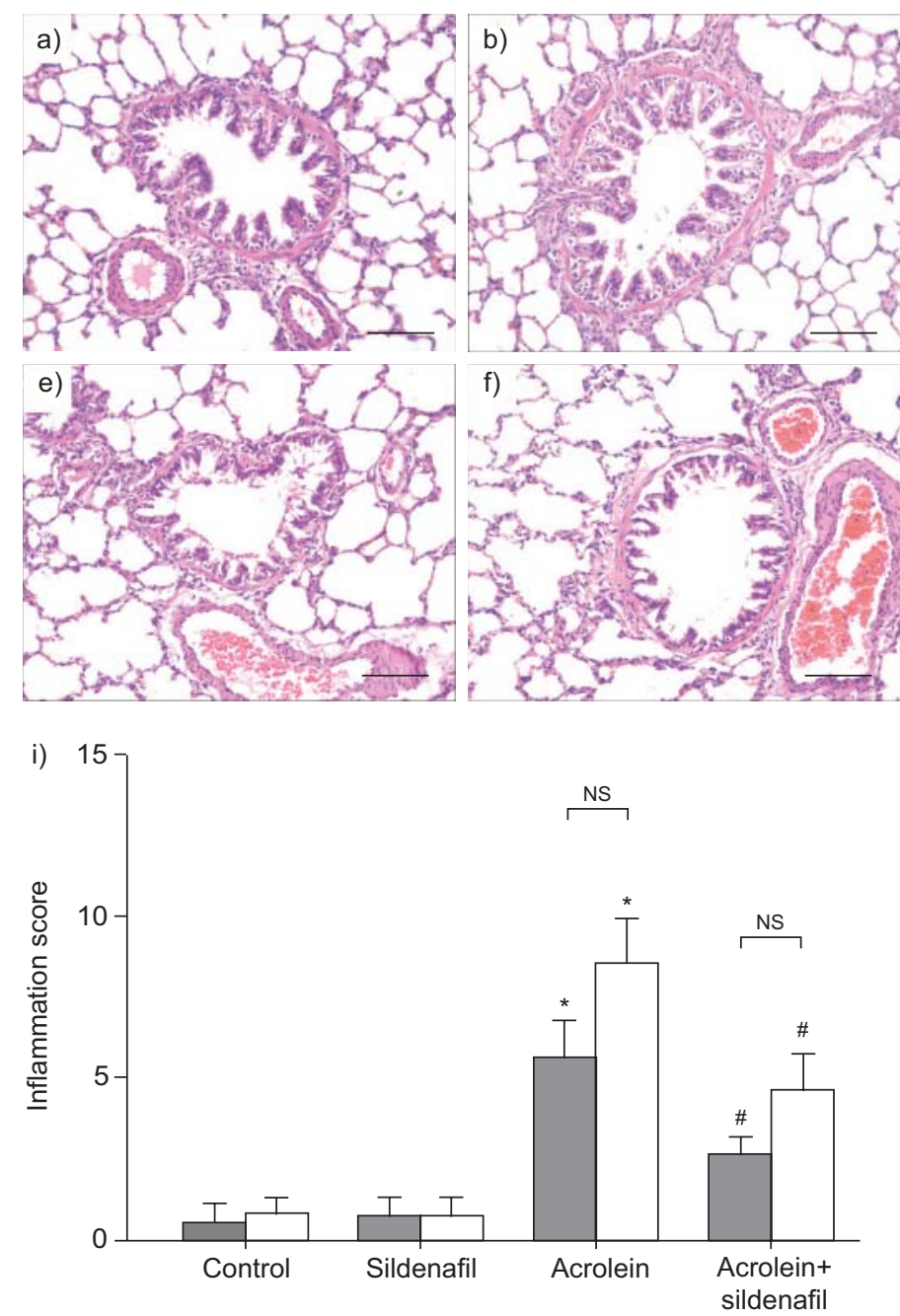

statistically significant differences in TNF- $\alpha$ and CINC-1 levels were found in sildenafil treatment between 14 and 28 days of acrolein exposure.

\section{Effect of sildenafil on histopathological changes in rat airways induced by acrolein exposure}

Histopathological changes of rat airways were examined by $\mathrm{H} \& \mathrm{E}$ and $\mathrm{AB} / \mathrm{PAS}$. After the repeated inhalation of acrolein, thickening of the airway epithelium, peribronchial inflammatory cell infiltration and lumen obstruction by mucus and cell debris could be detected by H\&E staining (fig. $4 a-h$ ). Inflammatory lesion scores were markedly increased in the acrolein-exposed rats, which were significantly inhibited by sildenafil pre-administration (fig. 4i). Moreover, a prominent increase in the numbers of goblet cells along the airway surface epithelium, as determined by AB/PAS, was observed after acrolein exposure (fig. $5 \mathrm{a}-\mathrm{h}$ ). Since goblet cell metaplasia extending to the small airways is a distinguishing feature of the lungs in acrolein-exposed rats [10], the percentage of the $\mathrm{AB} / \mathrm{PAS}$-positively stained area to the total epithelial area in the small airways was measured. The results suggested that the increase of $\mathrm{AB} / \mathrm{PAS}$ staining in airway epithelium, induced by acrolein exposure, was significantly inhibited by sildenafil treatment on both day 14 and 28. However, rats treated with
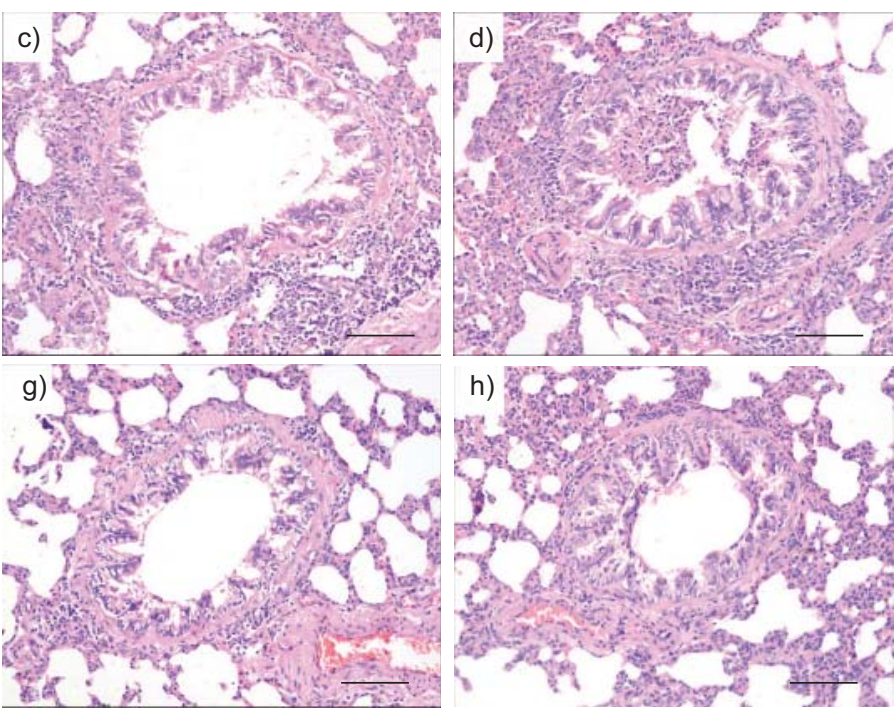

FIGURE 4. Histological changes in rat airways. Lung tissues from control rats at day a) 14 and b) 28 , rats exposed to acrolein alone at day c) 14 and d) 28, rats treated with sildenafil alone at day e) 14 and f) 28, and rats treated with acrolein plus sildenafil at day e) 14 and f) 28 were all analysed by haematoxylin and eosin staining. Scale bars $=100 \mu \mathrm{m}$. i) Lung inflammatory lesions for each animal were scored. Values are expressed as mean \pm SD (4-6 animals per group). *: $p<0.05$, significant difference from the control group; ${ }^{*}: p<0.05$ significant difference from the acrolein-exposed group. Ns: nonsignificant. $\square: 14$ days acrolein exposure; $\square$ : 28 days acrolein exposure.

acrolein plus sildenafil for 28 days tended to have a slight increase in pathological lesions compared with the rats under the same treatment for 14 days, but the difference was not statistically significant (figs $4 \mathrm{i}$ and $5 \mathrm{i}$ ). Taken together, these results implied that sildenafil could effectively attenuate, though failed to fully block, acrolein-induced airway inflammation and goblet cell metaplasia in rats.

\section{Effect of sildenafil on acrolein-induced Muc5ac mucin synthesis in rat lungs}

Muc5ac is the predominant mucin gene expressed in goblet cells. In order to investigate the effect of sildenafil on acroleininduced Muc5ac mucin synthesis in rat airway epithelium, immunohistochemistry for Muc5ac was performed on lung sections. Consistent with $\mathrm{AB} / \mathrm{PAS}$ staining results, the area positively stained by anti-Muc5ac monoclonal antibody in airway epithelium was increased markedly after acrolein exposure for 14 and 28 days, which could be significantly attenuated by sildenafil pretreatment (fig. 6). To quantify the changes of Muc5ac protein levels in rat lungs, western blot analysis was performed using lung homogenates. Results showed that sildenafil treatment significantly reduced the strong signal of the immunostained band for Muc5ac in the rat model (fig. 7a and $\mathrm{c} ; \mathrm{p}<0.05 ; \mathrm{n}=3$ ); meanwhile, there were no 


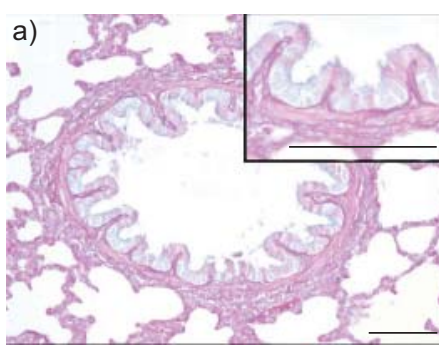

b)
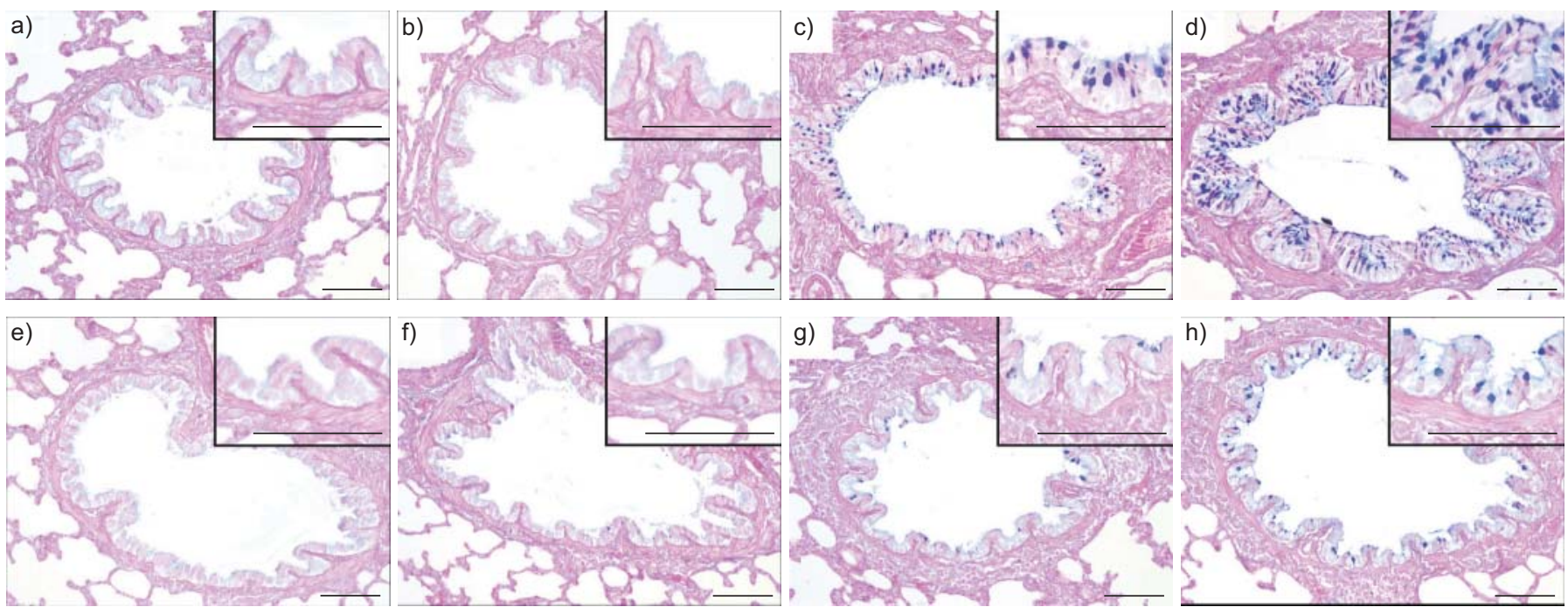

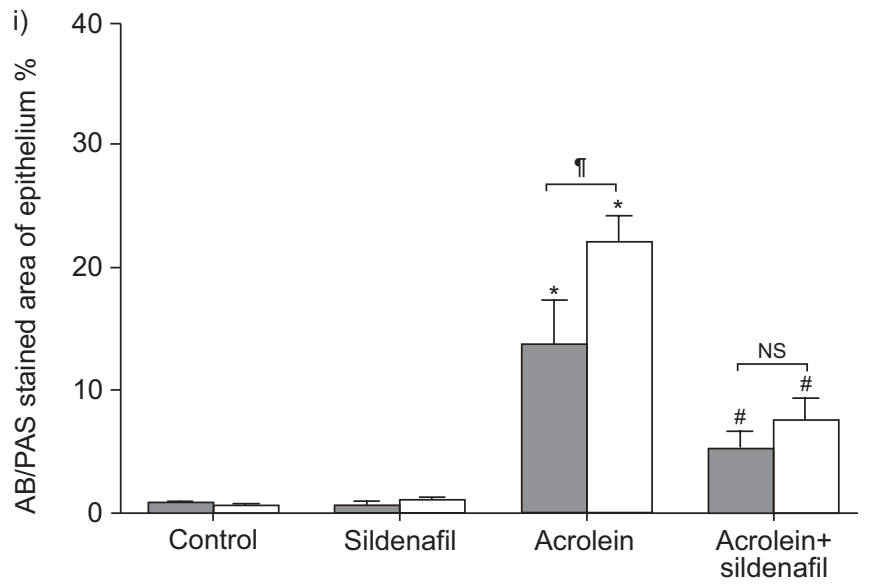

significant differences in sildenafil treatment between 14 and 28 days of acrolein exposure. To further examine Muc5ac gene expression at a transcriptional level, the steady-state mRNA levels for Muc5ac and $\beta$-actin in lung tissue were analysed by RT-PCR (fig. 7b) and quantified by densitometry (fig. 7d). The acrolein-induced accumulation of Muc5ac mRNA in rat lungs was also significantly inhibited by sildenafil administration $(\mathrm{p}<0.05 ; \mathrm{n}=3)$. Taken together, the results suggested that sildenafil could partially reduce acrolein-induced synthesis of Muc5ac at both mRNA and protein levels.

\section{DISCUSSION}

In the present study, the effect of sildenafil, a PDE5 inhibitor, on airway inflammation and mucus overproduction induced by acrolein inhalation was demonstrated in rats. Repeated exposure to acrolein, a major toxin and irritant in cigarette smoke, significantly decreased cGMP levels in lung tissue and increased leukocyte cell counts, as well as pro-inflammatory cytokine release in the BALF. Acrolein also induced lung NOmetabolite accumulation, airway inflammation, goblet cell hyperplasia and Muc5ac mucin synthesis in this rat model. The major finding of the present study is that sildenafil treatment significantly attenuated these pathological changes induced by acrolein exposure. The results also imply that the
FIGURE 5. Changes of alcian blue (AB)/periodic acid-Schiff (PAS) staining in rat airways. Lung tissues from control rats at a) 14 and b) 28 days, rats exposed to acrolein alone for c) 14 and d) 28 days, rats treated with sildenafil alone for e) 14 and f) 28 days, and rats treated with acrolein plus sildenafil for g) 14 and h) 28 days were analysed by AB/PAS staining. Scale bars $=100 \mu \mathrm{m}$. Inserts show higher magnification. i) The percentage of AB/PAS positively staining area to total epithelial area in rat airways. Values are expressed as mean \pm SD (4-6 animals per group). * : $\mathrm{p}<0.05$ significant difference from the control group; \# : $p<0.05$, significant difference from the acrolein-exposed group; $\because$ : $p<0.05$, significant difference between $14(\square)$ and $28(\square)$ days of acrolein exposure with or without sildenafil treatment. NS: nonsignificant.

inhibitory effect of sildenafil on airway inflammation may act through the NO/cGMP pathway.

Cyclic nucleotide second messengers (cyclic adenosine monophosphate (cAMP) and cGMP) play a central role in diverse signal transduction and regulation of various pathophysiological responses. Intracellular cGMP levels regulate cellular processes by activating protein kinases, directly gating specific ion channels, or altering other intracellular cyclic nucleotide (e.g. cAMP) concentrations through regulation of PDEs [34]. At the same time, cGMP levels in the tissue are controlled by a balance between the activities of sGCs, which catalyse the generation of cGMP, and the cyclic nucleotide PDEs, which catalyse the degradation of cGMP. These biochemical reactions are often affected by endogenous or exogenous compounds, including hormones, neurotransmitters, toxins, etc. [35]. Acrolein is one of the most reactive $\alpha, \beta$-unsaturated aldehydes present in tobacco smoke and is also formed during lipid peroxidation [4]. The acute toxicological effects of acrolein have been extensively studied, but the effects of subacute longterm exposure to acrolein on the NO/cGMP pathway are still unknown. A recent paper reported that acrolein administration $\left(4 \mathrm{mg} \cdot \mathrm{kg}^{-1}\right)$ for 3 or 7 days produced an increase in blood pressure associated with a decrease of cGMP levels in rat plasma [12]. The current study discovered that $3.0 \mathrm{ppm}$ 

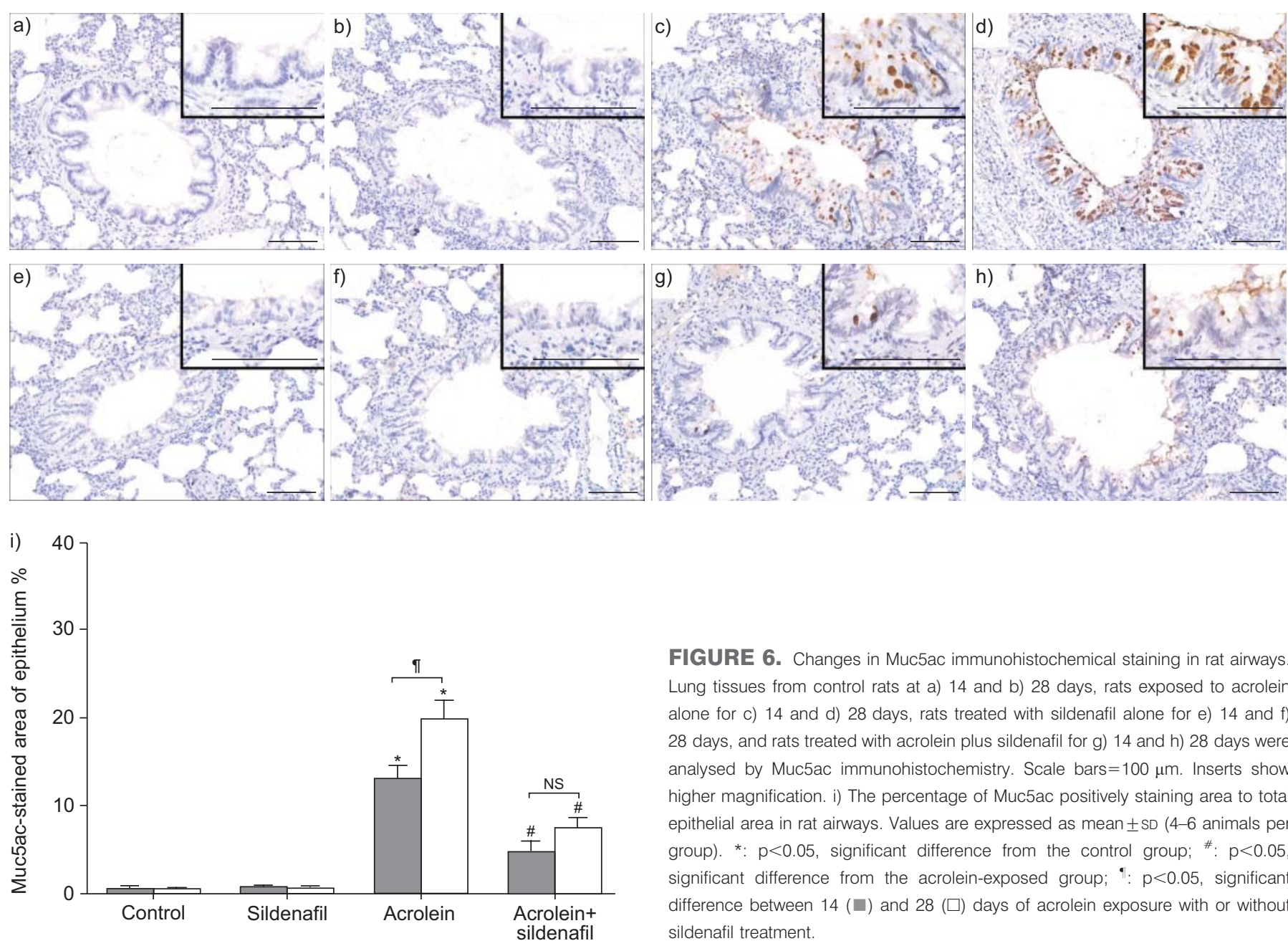

FIGURE 6. Changes in Muc5ac immunohistochemical staining in rat airways. Lung tissues from control rats at a) 14 and b) 28 days, rats exposed to acrolein alone for c) 14 and d) 28 days, rats treated with sildenafil alone for e) 14 and f) 28 days, and rats treated with acrolein plus sildenafil for g) 14 and h) 28 days were analysed by Muc5ac immunohistochemistry. Scale bars $=100 \mu \mathrm{m}$. Inserts show higher magnification. i) The percentage of Muc5ac positively staining area to total epithelial area in rat airways. Values are expressed as mean \pm SD (4-6 animals per group). ${ }^{*}: p<0.05$, significant difference from the control group; ${ }^{*}: p<0.05$, significant difference from the acrolein-exposed group; ${ }^{\top}: p<0.05$, significant difference between $14(\square)$ and $28(\square)$ days of acrolein exposure with or without sildenafil treatment.

acrolein inhalation for 14 and 28 days remarkably increased lung levels of NO-metabolites three to five times while significantly inhibiting cGMP generation by nearly $50 \%$ in rats (fig. 1). Despite the presence of ample amounts of NO that could activate sGC in rat lungs, it is interesting that cGMP levels were markedly reduced. One reason may be that excessive NO synthesis from iNOS could contribute to sGC downregulation in the lung $[20,36]$. Since the acrolein-induced decline of cGMP levels could be reversed by sildenafil treatment in the present study, PDE5 activity enhancement could also cause the cGMP reduction. Further study is warranted to more thoroughly address whether sGCs or PDEs or both were affected by acrolein exposure.

There is growing evidence that cGMP reduction is associated with lung injury and inflammation. It has recently been reported that sGC expression is reduced in the lungs of mice sensitised and challenged with ovalbumin [36]. In a murine model of LPS-induced lung injury, sGC inhibition worsens lung inflammation, which can be reversed by a cell-permeable cGMP analogue [37]. In CF respiratory epithelial cells, increasing cGMP levels correct multiple aspects of the CF pathological cascade, including defective protein glycosylation, bacterial adherence and pro-inflammatory responses [14]. In the present study, acrolein exposure caused a significant

cGMP reduction in rat lungs, along with inflammatory responses characterised by a leukocyte influx, TNF- $\alpha$ and CINC-1 release and increased lung histopathological lesions. Therefore, it would be worthwhile to test whether cGMP enhancers can exert some inhibitory effects on acroleininduced airway inflammation. Since PDE5 is the predominant PDE enzyme responsible for the degradation of cGMP in the lung, PDE5 inhibitors appear to hold potential for treating pulmonary disease. In primary cultures of rat alveolar epithelial cells, blockading PDE5 with zaprinast can reduce LPS-mediated IL-6 and TNF- $\alpha$ biosynthesis [38]. In tracheal smooth muscle cells, zaprinast also inhibits the TNF- $\alpha$-induced increase of iNOS expression and NO generation and reverses the TNF- $\alpha$-induced reduction of sGCs [17]. Compared with zaprinast, the earlier generation PDE5 inhibitor, sildenafil is much more potent at inhibiting PDE5. Recently, sildenafil has shown promise in clinical studies for treatment of lung diseases, such as primary or COPD-associated pulmonary hypertension [25, 26]. It also shows anti-inflammatory effects in certain animal models. For instance, in guinea pig models of airway disease, sildenafil inhibits airway hyperreactivity, leukocyte infiltration and NO generation after allergen exposure and exposure to endotoxin [29]. In mice challenged with bacterial aerosol, sildenafil reduces lung neutrophil infiltration [14]. The current data showed that sildenafil 

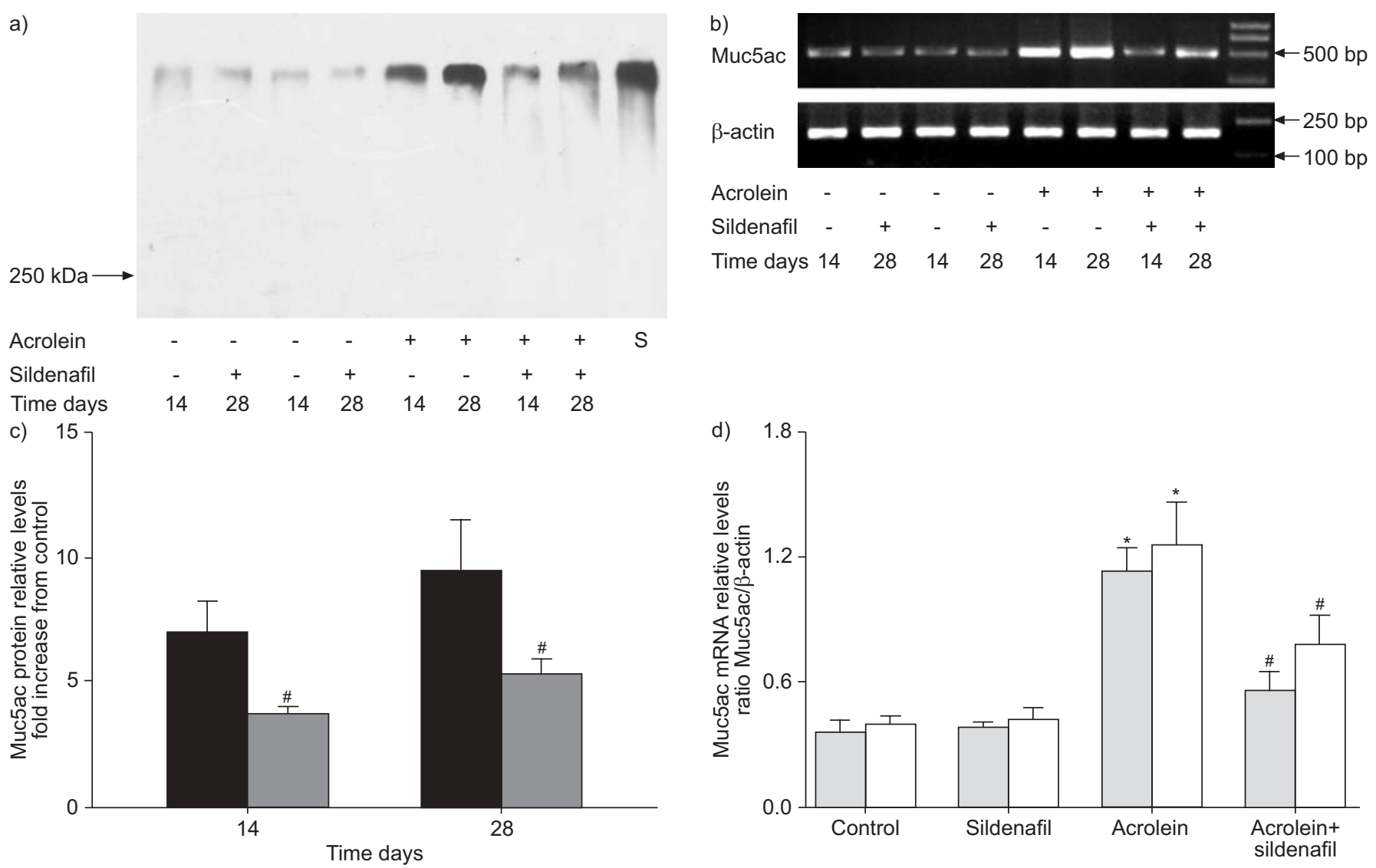

FIGURE 7. Changes in mucin Muc5ac mRNA and protein levels in rat lungs. Muc5ac protein levels were measured by a) western blotting and c) quantified by densitometry. The stomach Muc5ac glycoprotein was used as a positive control (S). The steady state of mRNA levels for Muc5ac was analysed by b) reverse transcriptase $\mathrm{PCR}$ and d) quantified by densitometry. Results shown in a) and b) are representative of three independent experiments. Values are expressed as mean \pm SD ( $\mathrm{n}=3$ ). *: $p<0.05$, significant difference from the control group; ${ }^{*}: p<0.05$, significant difference from the acrolein-exposed group. $\mathbf{\square}:$ acrolein; $\mathbf{\square}:$ acrolein+sildenafil; $\square 14$ days acrolein exposure; $\square: 28$ days acrolein exposure.

pretreatment significantly reduced acrolein-induced leukocyte influx and NO generation, as well as TNF- $\alpha$ and CINC-1 release, in both the BALF and lung tissue, which could be attributed to the consequent reversed intracellular cGMP levels in the lung.

A link between airway inflammation and mucus production has been suggested by both experimental and clinical observations over the past 15 yrs [1]. In healthy humans and animals, peripheral airways contain few or no identifiable goblet cells, but the number of AB/PAS-positive goblet cells and the amount of mucin produced within the surface of the epithelium are greatly increased after inflammatory stimulation [2]. Inflammatory mediators released during airway inflammation can interact with airway epithelial cells and activate intracellular signalling pathways, resulting in the overproduction of mucins. TNF- $\alpha$ can activate nuclear factor$\kappa \mathrm{B}$ in airway epithelium, leading to goblet cell metaplasia and mucus production in mice [39]. IL-1 $\beta$ is capable of inducing Muc5ac expression in human airway epithelium mediated by cyclooxygenase-2 and prostaglandin E2 [40]. In addition, NO has recently been reported to trigger protein kinase $C$ activation, resulting in Muc5ac overexpression in respiratory epithelial cells [41]. In the present study, sildenafil significantly attenuated acrolein-induced goblet cell metaplasia in rat airway epithelium, as suggested by histological analysis; and decreased Muc5ac synthesis at both mRNA and protein levels in the lung, as evidenced by RT-PCR and western blotting. The inhibitory effects of sildenafil on acrolein-augmented Muc5ac mucin synthesis in rat airways may be ascribed to the combined effects of the downregulation of pro-inflammatory mediators, such as TNF- $\alpha$, CINC- 1 and NO. However, one limitation of the current study is that the secretion of mucin was not measured. Intracellular mucin is synthesised and stored in cytoplasmic membrane-bound secretory granules. Upon external stimulation, the granules translocate to the cell periphery, where the granule membranes fuse with the plasma membrane and the mucin content is released into the airway lumen in a process of exocytosis regulated by a variety of interactive proteins or chemicals [42]. Mucus hypersecretion ultimately leads to airway plugging and bronchial obstruction. Further study is worthwhile to test whether mucin exocytosis is also altered by acrolein and sildenafil treatment.

In summary, subchronic inhalation of acrolein vapour could cause pronounced airway inflammation in rats characterised by a leukocyte influx, pro-inflammatory cytokine release, nitric oxide metabolite accumulation and goblet cell metaplasia with 
augmented mucin synthesis, which was associated with a significant reduction in lung cyclic guanosine 3',5'-monophosphate levels. The present authors demonstrated for the first time the benefits of sildenafil, a phosphodiesterase- 5 inhibitor, in attenuating acrolein-induced airway inflammation and mucus production, possibly through restoring the cyclic guanosine $3^{\prime}, 5^{\prime}$-monophosphate pathway. Since cigarette smoking is the most important risk factor initiating the development of chronic obstructive pulmonary disease, and among those chemical components of cigarette smoke, acrolein appears to play a critical role in mediating inflammatory processes, the results suggested that sildenafil might have therapeutic potential for treating chronic airway diseases. The relative tissue specificity of sildenafil, its tolerable side-effects and its proven safety make it an attractive therapeutic option that warrants further study.

\section{REFERENCES}

1 Voynow JA, Gendler SJ, Rose MC. Regulation of mucin genes in chronic inflammatory airway diseases. Am J Respir Cell Mol Biol 2006; 34: 661-665.

2 Rose MC, Voynow JA. Respiratory tract mucin genes and mucin glycoproteins in health and disease. Physiol Rev 2006; 86: 245-278.

3 Pauwels RA, Buist AS, Calverley PM, Jenkins CR, Hurd SS. Global strategy for the diagnosis, management, and prevention of chronic obstructive pulmonary disease. Am J Respir Crit Care Med 2001; 163: 1256-1276.

4 Kehrer JP, Biswal SS. The molecular effects of acrolein. Toxicol Sci 2000; 57: 6-15.

5 Rahman I, Adcock IM. Oxidative stress and redox regulation of lung inflammation in COPD. Eur Respir J 2006; 28: 219-242.

6 Facchinetti F, Amadei F, Geppetti P, et al. $\alpha, \beta$-unsaturated aldehydes in cigarette smoke release inflammatory mediators from human macrophages. Am J Respir Cell Mol Biol 2007; 37: 617-623.

7 Park YS, Kim J, Misonou Y, et al. Acrolein induces cyclooxygenase-2 and prostaglandin production in human umbilical vein endothelial cells. Arterioscler Thromb Vasc Biol 2007; 27: 1319-1325.

8 Zhang HQ, Forman HJ. Acrolein induces heme oxygenase- 1 through PKC- $\delta$ and PI3K in human bronchial epithelial cells. Am J Respir Cell Mol Biol 2008; 38: 483-490.

9 Leikauf GD, Leming LM, O'Donnell JR, Doupnik CA. Bronchial responsiveness and inflammation in guinea pigs exposed to acrolein. J Appl Physiol 1989; 66: 171-178.

10 Borchers MT, Wert SE, Leikauf GD. Acrolein-induced Muc5ac expression in rat airways. Am J Physiol Lung Cell Mol Physiol 1998; 274: L573-L581.

11 Borchers MT, Wesselkamper S, Wert SE, Shapiro SD, Leikauf GD. Monocyte inflammation augments acroleininduced Muc5ac expression in mouse lung. Am J Physiol Lung Cell Mol Physiol 1999; 277: L489-L497.

12 Yousefipour Z, Ranganna K, Newaz MA, Milton SG. Mechanism of acrolein-induced vascular toxicity. J Physiol Pharmacol 2005; 56: 337-353.

13 Ahluwalia A, Foster P, Scotland RS, et al. Antiinflammatory activity of soluble guanylate cyclase: cGMPdependent down-regulation of P-selectin expression and leukocyte recruitment. Proc Natl Acad Sci USA 2004; 101 1386-1391.

14 Poschet JF, Timmins GS, Taylor-Cousar JL, et al. Pharmacological modulation of cGMP levels by phosphodiesterase 5 inhibitors as a therapeutic strategy for treatment of respiratory pathology in cystic fibrosis. Am J Physiol Lung Cell Mol Physiol 2007; 293: L712-L719.

15 von Bülow V, Rink L, Haase H. Zinc-mediated inhibition of cyclic nucleotide phosphodiesterase activity and expression suppresses TNF- $\alpha$ and IL- $1 \beta$ production in monocytes by elevation of guanosine $3^{\prime}, 5^{\prime}$-cyclic monophosphate. $J$ Immunol 2005; 175: 4697-4705.

16 Kiemer AK, Hartung T, Vollmar AM. cGMP-mediated inhibition of TNF- $\alpha$ production by the atrial natriuretic peptide in murine macrophages. J Immunol 2000; 165: 175 181.

17 Wu BN, Chen CW, Liou SF, Yeh JL, Chung HH, Chen IJ. Inhibition of proinflammatory tumor necrosis factorinduced inducible nitric-oxide synthase by xanthine-based 7-[2-[4-(2-chlorobenzene)piperazinyl]ethyl]-1,3-dimethylxanthine (KMUP-1) and 7-[2-[4-(4-nitrobenzene)piperazinyl]ethyl]-1,3-dimethylxanthine (KMUP-3) in rat trachea: the involvement of soluble guanylate cyclase and protein kinase G. Mol Pharmacol 2006; 70: 977-985.

18 Gerassimou C, Kotanidou A, Zhou Z, Simoes DC, Roussos C, Papapetropoulos A. Regulation of the expression of soluble guanylyl cyclase by reactive oxygen species. Br J Pharmacol 2007; 150: 1084-1091.

19 Takata M, Filippov G, Liu H, et al. Cytokines decrease sGC in pulmonary artery smooth muscle cells via NO-dependent and NO-independent mechanisms. Am J Physiol Lung Cell Mol Physiol 2001; 280: L272-L278.

20 Filippov G, Bloch DB, Bloch KD. Nitric oxide decreases stability of mRNAs encoding soluble guanylate cyclase subunits in rat pulmonary artery smooth muscle cells. J Clin Invest 1997; 15: 942-948.

21 Farrow KN, Groh BS, Schumacker PT, et al. Hyperoxia increases phosphodiesterase 5 expression and activity in ovine fetal pulmonary artery smooth muscle cells. Circ Res 2008; 102: 226-233.

22 Witwicka H, Kobiałka M, Siednienko J, Mitkiewicz M, Gorczyca WA. Expression and activity of cGMP-dependent phosphodiesterases is up-regulated by lipopolysaccharide (LPS) in rat peritoneal macrophages. Biochim Biophys Acta 2007; 1773: 209-218.

23 Corbin JD, Beasley A, Blount MA, Francis SH. High lung PDE5: a strong basis for treating pulmonary hypertension with PDE5 inhibitors. Biochem Biophys Res Commun 2005; 334: 930-938.

24 Ballard SA, Gingell CJ, Tang K, Turner LA, Price ME, Naylor AM. Effects of sildenafil on the relaxation of human corpus cavernosum tissue in vitro and on the activities of cyclic nucleotide phosphodiesterase isozymes. J Urol 1998; 159: 2164-2171.

25 Galiè N, Ghofrani HA, Torbicki A, et al. Sildenafil citrate therapy for pulmonary arterial hypertension. $N$ Engl J Med 2005; 353: 2148-2157.

26 Alp S, Skrygan M, Schmidt WE, Bastian A. Sildenafil improves hemodynamic parameters in COPD - an investigation of six patients. Pulm Pharmacol Ther 2006; 19: 386-390. 
27 Ladha F, Bonnet S, Eaton F, Hashimoto K, Korbutt G, Thébaud B. Sildenafil improves alveolar growth and pulmonary hypertension in hyperoxia-induced lung injury. Am J Respir Crit Care Med 2005; 172: 750-756.

28 Zhao L, Mason NA, Morrell NW, et al. Sildenafil inhibits hypoxia-induced pulmonary hypertension. Circulation 2001; 104: 424-428.

29 Toward TJ, Smith N, Broadley KJ. Effect of phosphodiesterase-5 inhibitor, sildenafil (Viagra), in animal models of airways disease. Am J Respir Crit Care Med 2004; 169: 227-234.

30 Cohen IR, Altshuler AP. A new spectrophotometric method for the determination of acrolein in combustion gases and in the atmosphere. Anal Chem 1961; 33: 726-733.

31 Narasaraju TA, Jin N, Narendranath CR, Chen Z, Gou D, Liu L. Protein nitration in rat lungs during hyperoxia exposure: a possible role of myeloperoxidase. Am J Physiol Lung Cell Mol Physiol 2003; 285: L1037-L1045.

32 Barrett EG, Wilder JA, March TH, Espindola T, Bice DE. Cigarette smoke-induced airway hyperresponsiveness is not dependent on elevated immunoglobulin and eosinophilic inflammation in a mouse model of allergic airway disease. Am J Respir Crit Care Med 2002; 165: 1410-1418.

33 Mata M, Ruíz A, Cerdá M, et al. Oral N-acetylcysteine reduces bleomycin-induced lung damage and mucin Muc5ac expression in rats. Eur Respir J 2003; 22: 900-905.

34 Omori K, Kotera J. Overview of PDEs and their regulation. J Circ Res 2007; 100: 309-327.
35 Lucas KA, Pitari GM, Kazerounian S, et al. Guanylyl cyclases and signaling by cyclic GMP. Pharmacol Rev 2000; 52: 375-414.

36 Papapetropoulos A, Simoes DCM, Xanthou G, Roussos C, Gratziou C. Soluble guanylyl cyclase expression is reduced in allergic asthma, 2006; 290: L179-L184.

37 Glynos C, Kotanidou A, Orfanos SE, et al. Soluble guanylyl cyclase expression is reduced in LPS-induced lung injury. Am J Physiol Regul Integr Comp Physiol 2007; 292: R1448-R1455.

38 Haddad JJ, Land SC, Tarnow-Mordi WO, Zembala M, Kowalczyk D, Lauterbach R. Immunopharmacological potential of selective phosphodiesterase inhibition. I. Differential regulation of lipopolysaccharide-mediated proinflammatory cytokine (interleukin-6 and tumor necrosis factor $\alpha$ ) biosynthesis in alveolar epithelial cells. $J$ Pharmacol Exp Ther 2002; 300: 559-566.

39 Lora JM, Zhang DM, Liao SM, et al. Tumor necrosis factor- $\alpha$ triggers mucus production in airway epithelium through an IкB kinase $\beta$-dependent mechanism. J Biol Chem 2005; 280: 36510-36517.

40 Gray $T$, Nettesheim P, Loftin C, et al. Interleukin-1 $\beta$ induced mucin production in human airway epithelium is mediated by cyclooxygenase-2, prostaglandin E2 receptors, and cyclic AMP-protein kinase A signaling. Mol Pharmacol 2004; 66: 337-346.

41 Song JS, Kang CM, Yoo MB, et al. Nitric oxide induces Muc5ac mucin in respiratory epithelial cells through PKC and ERK dependent pathways. Respir Res 2007; 8: 28.

42 Davis CW, Dickey BF. Regulated airway goblet cell mucin secretion. Annu Rev Physiol 2008; 70: 487-512. 